\title{
Microsurgery and external fixation in orthoplastic reconstruction of tibial injuries
}

\section{Mikrochirurgie und externe Fixation bei der orthoplastischen Rekonstruktion von Tibiaverletzungen}

Authors

Francesca Toia ${ }^{1}$, Giovanni Zabbia ${ }^{1}$, Roberto Scirpo ${ }^{1}$, Roberto Pirrello ${ }^{1}$, Lorenzo Nalbone², Adriana Cordova ${ }^{1}$

Institutes

1 Section of Plastic and Reconstructive Surgery. Department of Surgical, Oncological and Oral Sciences. University of Palermo

2 Section of Orthopaedic Surgery. Department of Surgical, Oncological and Oral Sciences. University of Palermo

\section{Schlüsselwörter}

Mikrochirurgie, Interdisziplinäre plastische Chirurgie, Unterschenkelrekonstruktion, Interdisziplinäre plastische Chirurgie, orthoplastische Rekonstruktion, Fixateur externe

Key words

Microsurgery, orthoplastic reconstruction, lower limb reconstruction, external fixation

accepted 13.08.2019

submitted $\quad 01.02 .2019$

Bibliography

DOI https://doi.org/10.1055/a-1017-3013

Handchir Mikrochir Plast Chir 2019; 51: 484-491

(c) Georg Thieme Verlag KG Stuttgart · New York

ISSN 0722-1819

Correspondence Address

MD, PhD Francesca Toia

University of Palermo Section of Plastic and Reconstructive

Surgery. Department of Surgical, Oncological and Oral

Sciences

via del Vespro 129

90127 palermo

Tel.: 0916553409

Fax: 0916553409

E-Mail: francescatoia@gmail.com

\section{ZUSAMMENFASSUNG}

Hintergrund Die „Orthoplastie“ ist ein relativ neuer Ansatz zur Rekonstruktion der unteren Extremitäten, der eine Integration von plastisch-chirurgischer und orthopädischer Fachkompetenz sowie die Verfügbarkeit gut ausgestatteter
Einrichtungen erfordert. Die akute Verkürzung mit längerfristig angelegtem Rahmen zur Verlängerung gelten generell als Alternativen zum Längenerhalt mit mikrochirurgischer Weichteilrekonstruktion, doch gewinnt die integrierte Behandlung mit Fixateur externe und rekonstruktiver Mikrochirurgie zunehmend an Bedeutung und die gemeinsamen Ansätze werden weiter verfeinert.

Material und Methoden Es erfolgte eine retrospektive Analyse der Daten von sechzehn Patienten, die sich nach akuter oder chronischer Tibiaverletzung einem orthoplastischen Verfahren mit mikrochirurgischer Rekonstruktion der unteren Extremität und Fixateur externe unterzogen. Bei allen Patienten fand sich ein posttraumatischer Weichteildefekt in Verbindung mit einer Tibiafraktur vom Grad III nach Gustilo oder einer septischen Pseudarthrose der Tibia. Die Daten zu Art und Zeitpunkt der Knochen- und Weichteilrekonstruktion, Ergebnissen, Komplikationen und Notwendigkeit einer Reoperation wurden extrapoliert und mit denen einer historischen Patientengruppe verglichen, die orthopädisch behandelt worden war.

Ergebnisse In der orthoplastischen Gruppe wurden die Weichteile in den meisten Fällen mit einem anterolateralen Oberschenkellappen (ALT-Flap) rekonstruiert. Bei Patienten mit großflächigem Defekt war eine muskelschonende Vastuslateralis-Lappenplastik (VL) oder eine chimäre ALT-VL-Lappenplastik erforderlich. In der orthopädischen Gruppe wurden die Weichteile einer Sekundärheilung überlassen oder die Patienten wurden später an einen plastischen Chirurgen überwiesen. Ein statistischer Vergleich zwischen den beiden Gruppen ergab signifikante Unterschiede hinsichtlich folgender Daten: Zeit bis zur Heilung der Weichteile, Zeit bis zur knöchernen Durchbauung, Anzahl der Reinterventionen, Rate tiefer postoperativer Infektionen und Zeit bis zur Wiederaufnahme der Berufstätigkeit.

Schlussfolgerung Der orthoplastische Ansatz bei komplexen Beindefekten bietet im Vergleich zu orthopädischen Verfahren kürzere Behandlungszeiten und liefert bessere funktionelle Ergebnisse. Die Behandlung mit Fixateur externe und die mikrochirurgische Rekonstruktion müssen sich nicht gegenseitig ausschließen, sondern können in einem orthoplastischen Behandlungspfad miteinander kombiniert werden, um eine bestmögliche Rekonstruktion sowohl der Weichteile als auch des Knochens zu erzielen. 


\section{ABSTRACT}

Background "Orthoplastics" is a relatively new approach to lower limb reconstruction, where an integration of both plastic and orthopedic expertise is required, together with the availability of well-equipped facilities. Acute shortening and long-term frames for lengthening are generally considered alternatives to length preservation and soft tissue microsurgical reconstruction, but an integration of external fixation and reconstructive microsurgery is gaining an increasing role with refinements of joint approaches.

Material and methods Data on sixteen patients who underwent microsurgical lower limb reconstruction and external fixation with an orthoplastic approach, following acute or chronic tibial injury, were retrospectively reviewed. All patients presented a post traumatic soft tissue defect associated with a Gustilo III tibial fracture or a tibial septic pseudarthrosis. Data on type and timing of bone and soft tissue reconstruction, outcomes, complications and need for re-operation were extrapolated and compared to an historic group of patients treated with an orthopedic-based approach.

Results In the orthoplastic group, soft tissues were reconstructed with an ALT flap in most cases; a muscle-sparing VL or ALT-VL chimeric flap was necessary in cases with a very extensive defect. In the orthopedic group, soft tissues were left to heal by second intention or patients were lately referred to plastic surgeons. Statistical comparison between the two groups has showed significant differences on the following data: time for soft tissue healing, time to bone union, number of reinterventions, post-operative deep infection rate, time to return to work.

Conclusion The orthoplastic approach to complex leg defects yields shorter treatment time and better functional results compared to the orthopedic-based approach. External fixation and microsurgical reconstruction are not necessarily alternative procedures but can integrate in an orthoplastic path to address at best both soft tissue and bone reconstruction.

\section{Introduction}

Lower limb injuries represent, today, one of the most intricate challenge in trauma care, as they often involve severe osteocutaneous lesions, with extensive bone and soft tissues loss, with the risk of permanent and severe disabilities in most patients. For example, Gustilo IIIB high-energy fractures, usually associated with an insufficient soft tissue coverage. In addition to orthopedic fixation, these injuries also require soft tissue reconstruction, often in the form of a microvascular free flap [1, 2].

In the past decades, several studies have addressed the critical question whether amputation or limb salvage may guarantee a better outcome. Historically, primary treatment with amputation was strongly suggested, to avoid early complication such as infections and tissue necrosis propagation, with a significant lowering of life quality for patients. On the other hand, when salvage is the primary option, late bone infections, delayed bone union or non-union, venous insufficiency, represent additional post-operative criticisms that severely affect the restoration of limb structure and function [3, 4].

In recent years, efforts from different specialties, such as orthopedic, plastic and vascular surgery, strongly contributed, in the last decades, to important innovations that are significantly changing the approach to complex limb trauma. This multidisciplinary approach, described for the first time by Godina et al. in 1986, has allowed to achieve higher successful results in lower limb salvage [5]. Although this collaboration is, today, well recognized to be fundamental to better manage open limb fractures, it still remains in many hospitals an 'individual' work, with a primary orthopedic intervention and a secondary and delayed soft tissue reconstruction. However, it is now worldwide accepted that a better bone stabilization and healing is achieved when an early soft-tissue coverage is provided, offering a proper vascularization to resist infection and reduce the complication rate. In light of this, different studies have already shown the importance of a joint and multidisciplinary surgical team, where different expertise, mainly orthopedic and plastic surgery, are integrated in the whole treatment process [1, 6-11]. "Orthoplastic" reconstruction is, today, gaining increasing popularity, as recommended in the BAPRAS recommendation on open fractures of the lower limb [12].

The concept of interdisciplinary surgical care for complex lower extremities defects, with bone and soft tissue involvement, has exponentially evolved in the last decades, pointing out the importance of both functional and aesthetic outcomes as the primary goal of microsurgical reconstruction [13-15].

Several papers have shown the benefit of a combined approach in terms of functional outcomes, and more and more dedicated centers are developing all over the world [7, 8, 16]. The importance of a dedicated team, with orthopedic and plastic surgical skills (hold by the same surgeon or by several surgeons) and specific logistic requirements (as an operative room with a C-arm, an operative microscope and a comprehensive emergency service) has been widely recognized, but practical issues of plastic and orthopedic surgeons working together need to be addressed in order to further stimulate the growth of this surgical field. Unfortunately, this collaboration is not always easy, as well-coordinated facilities are often unavailable. Also, an integration of the plastic and orthopedic team is not often easy, even when the two teams are available at the same center. Finally, only few papers have already addressed practical issues commonly encountered during the development of an orthoplastic service and standard protocols are difficult to develop due to heterogeneity in clinical settings. Nevertheless, sharing experiences, especially on cases where complex procedures as microsurgical reconstruction and external fixation are required, can be of clinical help for the development of new potential orthoplastic centers.

Acute shortening and long-term frames for lengthening are generally considered alternatives to length preservation and soft tissue microsurgical reconstruction [17], but with the refinements in orthoplastic approaches, integration of external fixation and reconstructive microsurgery is gaining an increasing role in lower limb reconstruction [14]. 
In this paper, we report our experience in a recent established orthoplastic center, comparing data on the management of tibial Gustilo IIIB-IIIC fractures or tibial septic pseudarthrosis with an orthoplastic approach, to those of a previous orthopedic-based management at the same center.

\section{Materials and Methods}

Data on patients treated for an severe open tibial fracture (Gustilo IIIB or IIIC) or a tibial septic pseudarthrosis with an orthoplastic approach and receiving external fixation, in a single center, between 2015 and 2017 were retrospectively reviewed (orthoplastic group), and compared to data on patients previously treated at the same center with an orthopedic-based approach between 2013 and 2014 (control group).

Sixteen patients were identified in the orthoplastic group; 12 were men and 4 were women, with a mean age of 49 years (range: 17-84). Six patients presented a severe open tibial fracture (bone defect: $2-5 \mathrm{~cm}$ ) while 10 patients presented a tibial septic pseudarthrosis (bone defect: 2-6 cm-except for a $12 \mathrm{~cm}$ defect reconstructed with a free fibula transfer). Minimum follow up was 12 months.

Nineteen patients were identified in the orthopedic group; 16 patients were male and 3 were female, with a mean age of 52 years (range: 21-79). Ten patients presented a severe open tibial fracture (bone defect: $2-4 \mathrm{~cm}$ ) while 9 patients presented a tibial septic pseudarthrosis bone defect: $2-5 \mathrm{~cm}$ ). Minimum follow up was 12 months.

Perioperative protocols for trauma and septic patients will be presented and logistic aspects will be discussed.

Data on type and time of bone and soft tissue reconstruction were extrapolated. For outcomes evaluation, data on time for soft tissue healing, time to bone union, total length of hospitalization, number of reinterventions, wound complications, post-operative deep infection rate, return to work and need for special shoes were extrapolated from both groups and compared.

Statistical analysis was performed using a t-test for quantitative data.

\section{Results}

\section{Perioperative protocols}

In the orthoplastic group, patients with exposed fractures were treated in emergency by a general orthopedic and a plastic surgeon when initial debridement and bone fixation were performed, while all elective procedures were performed by a dedicated orthopedic and plastic surgery team. In all but one fracture, provisional fixation with a linear fixator was achieved, changed to a circular or hybrid fixation system at the time of soft tissue reconstruction. Evaluation of trauma cases by a dedicated orthoplastic team was undertaken within the following 24 hours on an elective setting and based on clinical and instrumental examination and operative reports. Definitive reconstruction was performed after a median of 5 days (range 3-9) as elective surgery. Patients with tibial pseudarthrosis were operated under elective conditions after a multidisciplinary evaluation by a dedicated orthopedic, plastic surgeon and infectiologist team (weekly clinic), and were invariably treated by a two stage operation. A bone biopsy was sent for microbiological testing before surgery, to guide the choose of the cement-antibiotic spacer and initial post-operative antibiotic therapy, which was later eventually modified based on microbiological analysis of the debrided bone. In the first stage, internal hardware removal, radical sequestrectomy and debridement were performed, and a circular or hybrid fixator was positioned. In all but one case, an antibiotic cement spacer was used to fill the gap and an ALT flap was raised from the contralateral limb for soft tissues reconstruction and adequate coverage. Most commonly isolated bacteria were Staphylococcus aureus, followed by Pseudomonas aeruginosa; Acinetobacter baumani, Enterobacter cloacae, Enterobacter faecalis and Proteus mirabilis were less frequently isolated. All patients received intravenous targeted antibiotics for 4 to 6 weeks, followed by a four-week oral antibiotic therapy. After a median of 3 months (range: 3-4), the flap was raised, and the spacer replaced with a cancellous bone graft harvested from the iliac crest in all but one case. In one case, no free flap was transferred in the first stage, where the wound was left open following extensive bone debridement and external fixation; a fibula free flap from the contralateral leg was transferred 3 months afterwards. Of note, all cases resulted from previous exposed tibial fracture treated with an orthopedic-based approach, in which a soft tissue defect was allowed to heal by secondary intention. Perioperative orthoplastic protocols for trauma and septic patients are summarized in $>$ Fig. $\mathbf{1}$ and $>$ Fig. 2 .

For microsurgical reconstruction, skin incisions were planned, and soft tissue debridement performed; then flap raising was performed simultaneously to eventual definitive bone fixation (for the trauma subgroup) or simultaneously to bone debridement, osteomyelitis focus and eventual hardware removal (for the septic subgroup). To optimize human resources and timing, once the need for soft tissue microsurgical reconstruction is recognized, it is an option to isolate recipient vessels before bone fixation; the flap can be elevated during orthopedic surgery, from the incisional skin incision. Flap incisions (thus definitive size of the flap) and height for vessels anastomosis are better decided once bone fixation is completed.

After measuring the length of the fixator connecting bars and positioning the limb for microvascular anastomosis, the operative microscope was positioned for anastomosis and the bars were partially or totally removed to facilitate access to the recipient vessels. The flap was then transferred, anastomosis performed, and bars repositioned before dressing. After surgery, all patients were hospitalized at the plastic surgery guard, where the whole nursing and medical team is versed in flap monitoring. After a median of 9 days, they were discharged and followed at the orthoplastic outpatient clinic (weekly follow-up until wound healing and then monthly follow up or transferred to the infectious disease unit, if in need of parenteral antibiotic treatment. The plastic surgeon who performed the surgery (or one who assisted the flap transfer) was available for eventual re-exploration during the first 5 postoperative days. Flap raising for second stage or secondary surgery was always performed by a dedicated plastic surgeon, to avoid complications due to inadequate incisions or flap handling.

In the orthopedic group, both acute and chronic patients were initially treated by the orthopedic team only; soft tissue defects were treated with dressings, VAC therapy or coverage with dermal substitutes and eventually lately referred to the plastic surgery team. 


\section{INITIAL EVALUATION}

Joint evaluation (weekly orthoplastic clinic)

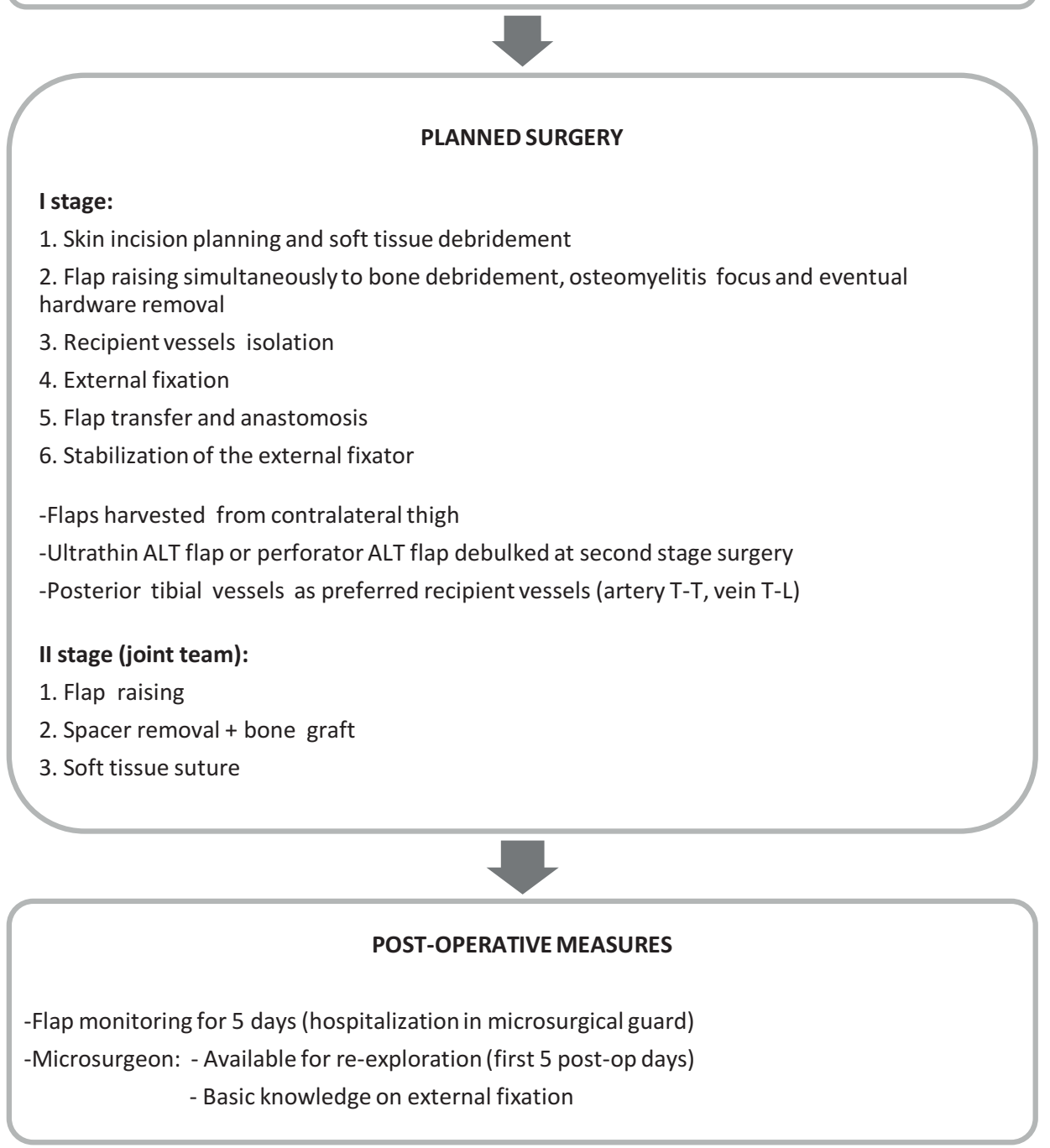

- Fig. 1 Perioperative orthoplastic protocol for tibial fractures.

\section{Type and timing of bone and soft tissue reconstruction}

All cases in the orthoplastic group were initially treated with microsurgical reconstruction and external fixation. Soft tissues were reconstructed with an ALT flap in most cases; a muscle-sparing VL or ALT-VL chimeric flap was necessary in 2 cases with a very extensive defect, not allowing for primary closure of an eventual ALT flap only. The ALT flap was raised suprafascially in most cases, and suprascarpal in the last 6 cases of our series ( 2 tibial fractures and 4 tibial pseudarthrosis). Most suprafascial flaps were thinned at the time of bone grafting, while no thinning was required for the suprafascial flaps. The posterior tibialis were the preferred recipient vessels. Termino-lateral anastomosis was preferred for the artery in the absence of vascular damage, while a termino-terminal anas- tomosis was performed on interrupted posterior tibial artery; termino-terminal anastomosis was preferred for vein(s). In 3 acute cases, conversion to plate (1 case) or intramedullary nail (2 case) were performed, while 3 cases were treated by long-term frames. Secondary bone grafting (cancellous bone graft from the iliac crest) was required in 1 case in the trauma subgroup and 1 case in the septic subgroup.

In the orthopedic group, soft tissue defects were treated with VAC-Therapy ( 10 cases), dressings ( 7 cases) and dermal substitute (2 case). Of these, 5 were secondarily referred to plastic surgeons due to no healing (referral delay: 1-13 months, mean 8 months) and received reconstruction with a free flap. 


\section{EMERGENCY STRATEGY}

1. Emergency exploration (general plastic and orthopedic surgeon \pm vascular surgeon) (at arrival):

- Damage balance

- Initial debridement

- Temporary bone fixation

2. "Orthoplastic" evaluation and further planning (within $\mathbf{2 4}$ hours)

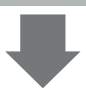

\section{PLANNED SURGERY}

1. Skin incision planning and soft tissue debridement

2. Recipient vessels isolation

3. Flap raising simultaneously to eventual definitive bone fixation

4. Flap transfer and anastomosis

5. Stabilization of the external fixator

- Flaps harvested from contralateral thigh

- Ultrathin ALT flap for moderate size defect/muscle-sparing VL or chimeric ALT-VL flap for extensive defect

- Posterior tibial vessels as preferred recipient vessels (artery T-T, vein T-L)

-Fig. 2 Perioperative orthoplastic protocol for tibial septic pseudoarthrosis. ${ }^{*}$ A different approach was used for reconstruction with a free fibula graft, see text.

\section{Outcomes}

Statistical comparison between the two groups has showed significant differences on the following data: time for soft tissue healing, time to bone union, number of reinterventions, post-operative deep infection rate, time to return to work.

Both time to soft tissue and bone healing were significantly shorter in the orthoplastic group (mean 4 vs 30 weeks for soft tissue healing, mean 10 vs 18 months for bone healing). Results are summarized in $>$ Table 1.

In the orthoplastic group, all soft tissues free flaps survived; only in one case a minor reoperation was required due to a partial wound dehiscence. There were 2 marginal necrosis and 1 further wound dehiscence solved with conservative treatment. There was no significant donor site morbidity, both in terms of functional defects and aesthetic aspect (no graft was needed). In the orthopedic group, 15 wounds healed by second intention; all 4 secondary free flaps healed uneventfully. Deep infection rate following leg fracture was significantly reduced in the orthoplastic group compared to the orthopedic group ( $17 \%$ and $50 \%$ respectively).

In the orthoplastic group, 3 patients needed major reoperation (excluding two-stage planned surgery): 2 patients required a bone graft and 1 patient a fixation revision due to fracture misalignment; in the orthopedic group 4 patients needed a secondary bone de- 
- Table 1 Statistical analysis of outcomes data. Data marked with * in the orthoplastic group are significantly different compared with the orthopedic group.

\begin{tabular}{|l|l|l|}
\hline & Orthoplastic approach & Orthopedic approach \\
\hline Time for soft tissue healing & $3-6$ (mean 4 weeks) & \\
\hline Time for bone reunion & $8-15$ (mean 10) months & $25-35$ (mean 30) weeks \\
\hline Re-interventions & $19 \%^{*}$ & $10-29$ (mean 18) months \\
\hline Post-operative deep infection rate & $17 \%^{*}$ & $53 \%$ \\
\hline Time to return to work or previous activities & $11-19($ mean 13$)$ months & $50 \%$ \\
\hline Total length of hospitalization & $14-50(42)$ days & $15-34$ (mean 20) months \\
\hline Need for special shoes & $25 \%$ & $52-61$ (mean 55) days \\
\hline
\end{tabular}

bridement , 5 patients required a secondary free flap reconstruction ( 1 for fracture coverage and 4 patients who developed septic pseudarthrosis), mean number of reoperations between the two study group being significantly different.

Mean time for return to work or previous activities was significantly shorter in the orthoplastic group (mean: 13 vs 20 months).

Conversely, differences on total length of hospitalization (41 vs 55 days) and need for special shoes ( $25 \%$ vs $32 \%$ ) were not significant.

Our study confirms that the orthoplastic approach to complex leg defects yields better outcomes compared to the orthopedic-based approach. Also, it anticipates the need for plastic surgery ( $16 \%$ late referral in our orthopedic-based group), avoiding an unnecessary delay and lengthening of treatment.

As shown by other papers, we confirm that external fixation and microsurgical reconstruction are not necessarily alternative to one another and can integrate in an orthoplastic path to address at best both soft tissue and bone reconstruction.

While external fixation is generally indicated in chronic septic cases, internal fixation is often preferred in acute cases, due to its advantages on bone defect healing, stability and patient comfort. Also, it facilitates flap insetting, although this benefit was more significant before the spread of orthoplastic techniques, when orthopedic and plastic surgery procedures were often sequential rather than simultaneous. However, there is not a conclusive evidence in the literature on the use of internal vs external fixation $[18,19]$. Early conversion to internal fixation is generally recommended, but long term frames find indications in case of delay in soft tissue reconstruction, gross contamination, or complex fracture patterns [12].

The main differences between the two groups in this series was in the time to soft tissue healing and to bone healing. These differences mainly rely on differences on time to soft tissue reconstruction, as in the orthopedic groups, soft tissue defects were left to heal by second intention or lately referred for microsurgical reconstruction, whereas in the orthoplastic group the need for flap reconstruction was always addressed and in acute cases reconstruction was undertaken within the first 7 days.

Specific timing in the overall management of limb reconstruction is definitely important. The concept of emergency free flaps is not recent, but the time elapsed from the debridement to the coverage is still a subject of discussions. Initially, Lister et al defined as "emergency" those free flaps used within 24 hours after debridement [20]. He suggested this interval as safe limit from the point of view of microbial contamination. Considering that microbial contamination could be held within acceptable limits for a longer period if the debridement is correctly performed, Godina extended this time frame to 72 hours, describing the "early free flap" procedure [5]. Ninkovic et al promoted a new classification, considering as primary free flaps those performed between 12 and 24 hours from debridement, and as delayed primary free flaps when performed between 2-7 days from the debridement [21, 22]. Georgescu et al completed this classification by adding the category of immediate emergency flaps, which refers to the flaps performed immediately after the debridement, including an "all-in-one reconstruction" [23]. Today, a 7 days period is generally accepted as safe for soft tissue reconstruction of open tibial fracture [12].

Differences in total hospital stay was not statistically significant between the two groups, which may be influenced by the need for hospital stay in septic cases requiring intravenous antibiotic surgery.

We also report practical aspects of complex lower limb reconstructions requiring microsurgery and external fixation.

Specific competences and structural requirements are necessary -not only for surgery- but also for the entire perioperative and follow-up patient management. Thus, these patients should best be treated in reference centers with a dedicated orthoplastic team. However, despite the increasing number of papers on guidelines and on outcomes of "orthoplastic" reconstruction, literature on standard criteria for reference centers and operative protocols is still scant and sharing experience on practical aspects can be beneficial to the development of this reconstructive field.

Ideally, traumatic patients should be explored at the emergency room from a dedicated team, as a joint evaluation from the very beginning allows a better damage balance and correct placement of skin incisions, which facilitates further treatment planning. Unfortunately, only few centers can provide h24 availability of both dedicated orthopedic and plastic surgeons, and alternative solutions should also be considered; as a second option, emergency exploration could be undertaken by general orthopedic and plastic surgeons (and eventually vascular surgeons) with basic knowledge on lower limb trauma, provided that the team holds microsurgical competences for an eventual emergency vascular repair. In our center, an emergency plastic microsurgery and orthopedic 
service is available h24, which takes care of the emergency treatment including damage balance, debridement and temporary bone fixation, while evaluation by a dedicated orthoplastic team is undertaken within the following 24 hours. Eventual further debridements are planned and microsurgical reconstruction ideally performed within 1 week.

Management of elective cases is, somehow, logistically easier; in our center, patients are evaluated (in a weekly clinic) and operated by a dedicated orthoplastic team. Also, elective cases are easier to handle intraoperatively, as surgical plan and timing are mostly decided in advance. In our practice, most of the initial cases were elective, which helped building a solid cooperation among plastic and orthopedic surgeons and involving dedicated infectiologists in the team. On this basis, an improved collaboration in the emergency setting was also possible.

While a plastic and an orthopedic surgeon performed together the initial exploration of traumatic cases, delayed and elective microsurgical reconstruction and external fixation were always performed by two teams working closely but simultaneously.

Recipient vessels isolation is generally performed before external fixation, so that the frame does not interfere with surgical dissection; during the orthopedic surgery then, the eventual need for more proximal vessels dissection is taken into account. Besides that, the plastic surgeon must have the basic knowledge to handle the external fixator and remove and reposition the connecting bars as needed, without compromise the orthopedic work in case of need for re-exploration.

In this clinical series, microsurgical flaps were always harvested from the thigh, preferentially from the contralateral one to extend the working space of the two teams. An ALT flap was used in most cases, and a muscle-sparing VL or a chimeric ALT- VL was used for extensive traumatic defects [24].

Several studies have demonstrated the potential of the thigh as a donor of soft tissues microsurgical flaps, which -elevated at different layers, and engineered in different configuration- can reconstruct a wide spectrum of defects [14, 15, 25-29]. The anterolateral thigh (ALT) flap have been extensively used for lower limb reconstruction; it allows a two team approach, requires no patient positioning change and is associated with a low donor site morbidity. However, Latissimus dorsi (LD) flap is the traditional workhorse flap for reconstruction of extensive defects [30], despite having being often replaced by ALT flap for moderate size defects. Muscle flaps are traditionally favoured due to their supposed role on bone healing and infection control, although fasciocutaneous and perforator flaps have recently believed to be as safe as muscle flaps [12]. Several muscle and perforator flaps must be present in the armamentarium of the reconstructive surgeons, with the LD flap playing a central role for very extensive defects. However, the associated donor-site morbidity, in terms of functional limitations of the shoulder motion, particularly during the early postoperative period, impairs the early assisted ambulation in lower limb patients; also, its harvest requires a change in patient positioning and prevents two teams from working simultaneously, thus lengthening the operative time [16, 31].

In our group, LD flap was frequently used in the past for very extensive defects, but we have progressively switched to the used of VL or ALT-VL flaps.
Our group has an extensive experience with the muscle sparing VL flaps, not limited to lower limb reconstruction, which can also reconstruct almost circumferential leg defects, alone on in a combination with an ALT flap (chimeric flap), and we feel that VL and chimeric ALT-VL flaps are still underexploited in leg reconstruction [24,32].They allows to reconstruct extensive defects, with a good contour profile and a low donor site morbidity. However, due to similar functional and better aesthetic outcomes with perforator flaps [33, 34], in order to minimize morbidity and improve results, ALT flap is usually preferred if primary closure is possible after its harvest, and we prefer to reserve the VL flap for extensive defects only.

Also, recent efforts on improving the aesthetic aspects of post-traumatic reconstruction have introduced novel thin variants of perforator flaps, as the suprascarpal (superthin) ALT flap, which have proved safe and better adapt to the thin leg profile [35-41].

In our experience, the use of the suprascarpal flap allowed to improve results in definitive reconstructions, achieving a better contour without secondary debulking procedures. When a secondary surgery is anticipated, as in tibial pseudarthrosis in this series, harvesting a thinner flap seems safer than secondary thinning during the second stage planned surgery, and reduce the need for a further tertiary surgery for flap debulking. We have recently switched to the harvest of suprascarpal flap in most cases, and - although small - our case series suggest its safety even when a second stage surgery with flap raising and bone graft is required.

A joint approach with a clear operative protocol allowed to better plan the entire clinical path from the beginning and to optimize timing of surgery. This is particularly important in elderly patients, which are more prone to systemic complications following prolonged surgery and hospitalization.

This study presents several limitations. It is a retrospective study on a limited clinical series and only trauma and septic cases are included; evaluation of functional outcomes is incomplete as data on LEFS were not available for all patients. However, the main aim of this paper was to focus on the role of microsurgical reconstruction in complex lower limb injuries treated with external fixation and to share clinical protocols for optimizing joint approach to lower limb reconstruction.

\section{CONCLUSION}

Orthoplastic approach to complex leg defects yields shorter treatment time and better functional results compared to orthopedic-based approach. External fixation and microsurgical reconstruction are not necessarily alternative procedures but can integrate in an orthoplastic path to address at best both soft tissue and bone reconstruction.

\section{Conflict of interest}

The authors declare that they have no conflict of interest 


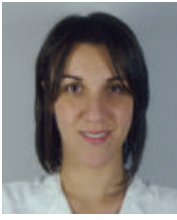

\section{Dr. Francesca Toia}

is an Assistant Professor in Plastic Surgery at University of Palermo. Her main interests are reconstructive microsurgery, hand and lower limb surgery, and her main research field is nerve regeneration. She holds several international fellowships and a PhD on Experimental Oncology and Surgery.

\section{References}

[1] Gopal S et al. Fix and flap: the radical orthopaedic and plastic treatment of severe open fractures of the tibia. J Bone Joint Surg Br 2000; 82 (7): 959-966

[2] Rohde $\mathrm{C}$ et al. Gustilo grade IIIB tibial fractures requiring microvascular free flaps: External fixation versus intramedullary rod fixation. Ann Plast Surg 2007; 59 (1): 14-17

[3] Mundy LR et al. Acute Treatment Patterns for Lower Extremity Trauma in the United States: Flaps versus Amputation. J Reconstr Microsurg 2017; 33 (8): 563-570

[4] Xiong $L$ et al. Free flaps for reconstruction of soft tissue defects in lower extremity: A meta-analysis on microsurgical outcome and safety. Microsurgery 2016; 36 (6): 511-524

[5] Godina M. Early microsurgical reconstruction of complex trauma of the extremities. Plast Reconstr Surg 1986; 78 (3): 285-292

[6] Sommar $\mathrm{P}$ et al. Effects of a formalized collaboration between plastic and orthopedic surgeons in severe extremity trauma patients; a retrospective study. J Trauma Manag Outcomes 2015; 9: 3

[7] Boriani $\mathrm{F}$ et al. Orthoplastic surgical collaboration is required to optimise the treatment of severe limb injuries: A multi-centre, prospective cohort study. J Plast Reconstr Aesthetic Surg 2017; 70: 715-722

[8] Lerman OZ, Kovach S], Levin LS. The respective roles of plastic and orthopedic surgery in limb salvage. Plast Reconstr Surg 2011; 127: 215-227

[9] Cho EH et al. Muscle versus Fasciocutaneous Free Flaps in Lower Extremity Traumatic Reconstruction: A Multicenter Outcomes Analysis. Plast Reconstr Surg 2018; 141 (1): 191-199

[10] J. Jordan, D., Malahias, M., Khan, W. \& Hindocha, S. The Ortho-Plastic Approach to Soft Tissue Management in Trauma. Open Orthop. J. 8, 399-408 (2014)

[11] Heitmann C, Levin LS. The Orthoplastic Approach for Management of the Severely Traumatized Foot and Ankle 2003; 54: (2): 379-390

[12] BOA/BAPRAS Standards for the management of open fractures of the lower limb. Im Internet: http://www.bapras.org.uk/professionals/clinical-guidance/open-fractures-of-the-lower-limb; last date of access: october 7th, 2019

[13] Rodriguez ED et al. Functional outcomes of posttraumatic lower limb salvage: A pilot study of anterolateral thigh perforator flaps versus muscle flaps. J Trauma - Inj Infect Crit Care 2009; 66: 1311-1314

[14] Song Y, Qi X, Shen J. Free Flap Combined with External Fixator in the Treatment of Open Fractures of the Calf. Cell Biochem Biophys 2014; 70: 549-552

[15] Ciudad $P$ et al. A simple and effective method to optimize limb position after complex lower limb free flap reconstruction with concurrent external fixation. Microsurgery 2018; 2-3

[16] Bar-Meir E et al. Combined Iliazarov and free flap for severe recurrent flexion-contracture release. J Burn Care Res 2006; 27: 529-534

[17] Salih S, Mills E, McGregor-Riley J et al. Transverse debridement and acute shortening followed by distraction histogenesis in the treatment of open tibial fractures with bone and soft tissue loss. Strateg Trauma Limb Reconstr 2018; 13 (3): 129-135

[18] Meng YC, Zhou XH. External fixation versus open reduction and internal fixation for tibial pilon fractures: A meta-analysis based on observational studies. Chinese J Traumatol - English Ed 2016; 19: 278-282
[19] Rayan A et al. Open reduction internal fixation versus external fixation with limited internal fixation for displaced comminuted closed pilon fractures: A randomised prospective study. J Orthop Trauma Rehabil 2018; 24: 84-89

[20] Lister G, Scheker L. Emergency free flaps to the upper extremity. J Hand Surg Am 1988; 13 (1): 22-28

[21] Herter F, Ninkovic M, Ninkovic M. Rational flap selection and timing for coverage of complex upper extremity trauma. Journal of Plastic, Reconstructive and Aesthetic Surgery 2007; 60 (7): 760-769

[22] Ninković M, Schoeller T, Benedetto KP et al. Emergency free flap cover in complex injuries of the lower extremities. Scand J Plast Reconstr Surg Hand Surg 1996; 30 (1): 37-47

[23] Georgescu AV, Ivan O. Emergency free flaps. Microsurgery 2003; 23 (3): 206-216

[24] Toia F et al. Segmental anatomy of the vastus lateralis: Guidelines for muscle-sparing flap harvest. Plast Reconstr Surg 2015; 135: (1): 185e-198e

[25] Agostini T, Lazzeri D, Spinelli G. Anterolateral thigh flap: Systematic literature review of specific donor-site complications and their management. J Cranio-Maxillofacial Surg 2013; 41: 15-21

[26] Lakhiani C, Lee MR, Saint-Cyr M. Vascular anatomy of the anterolateral thigh flap: A systematic review. Plast Reconstr Surg 2012; 130: 1254-1268

[27] Marchaland JP, Ollat D, Mathieu L et al. How to cover soft-tissue defects after injuries to the leg in precarious conditions. Eur J Trauma Emerg Surg 2009; 35: 3-9

[28] Zheng X et al. Reconstruction of complex soft-tissue defects in the extremities with chimeric anterolateral thigh perforator flap. Int I Surg 2016; 26: 25-31

[29] Posch NAS, Mureau MAM, Flood SJ et al. The combined free partial vastus lateralis with anterolateral thigh perforator flap reconstruction of extensive composite defects. Br J Plast Surg 2005; 58: 1095-1103

[30] Cavadas PC, Teran-Saavedra PP. Combined latissimus dorsi thoracodorsal artery perforator free flap: The 'razor flap'. J Reconstr Microsurg 2002; 18 (1): 29-31

[31] Lee KT, Mun GH. A systematic review of functional donor-site morbidity after latissimus dorsi muscle transfer. Plast Reconstr Surg 2014; 134: 303-314

[32] D'arpa $S$ et al. Variability and reliability of the vastus lateralis muscle anatomy. Acta Chir Belg 2016; 116: (4): 203-212

[33] Philandrianos $C$ et al. Soft Tissue Coverage in Distal Lower Extremity Open Fractures: Comparison of Free Anterolateral Thigh and Free Latissimus Dorsi Flaps. J Reconstr Microsurg 2018; 34 (2): 121-129

[34] Tamimy MS et al. Has the anterolateral thigh flap replaced the latissimus dorsi flap as the workhorse for lower limb reconstructions? J Pak Med Assoc 2010; 60 (2): 76-81

[35] Hong JP, Choi DH, Suh H. A new plane of elevation: the superficial fascial plane for perforator flap elevation. J Reconstr Microsurg 2014; 30: 491-496

[36] Diamond S, Seth AK, Chattha AS et al. Outcomes of Subfascial, Suprafascial, and Super-Thin Anterolateral Thigh Flaps: Tailoring Thickness without Added Morbidity. J Reconstr Microsurgn 2018; 34: 176-184

[37] Fox P, Endress R, Sen $S$ et al. Fascia-only anterolateral thigh flap for extremity reconstruction. Ann Plast Surg 2014; 72: 9-13

[38] Xie $S$ et al. Reconstruction of foot and ankle defects with a superthin innervated anterolateral thigh perforator flap. J Plast Surg Hand Surg 2016; 50: 367-374

[39] Maruccia M et al. Suprafascial versus traditional harvesting technique for free antero lateral thigh flap: A case-control study to assess the best functional and aesthetic result in extremity reconstruction. Microsurgery 2017; 37: 851-857

[40] Seth AK, lorio ML. Super-Thin and Suprafascial Anterolateral Thigh Perforator Flaps for Extremity Reconstruction. J Reconstr Microsurg 2017; 33: 466-473

[41] Bhadkamkar MA et al. The ultra-thin, fascia-only anterolateral thigh flap. J Reconstr Microsurg 2014; 30: 599-605 